\title{
Is It Possible to Protract the Maxilla by Surgically Assisted Rapid Maxillary Expansion and Intermaxillary Class III Elastics?
}

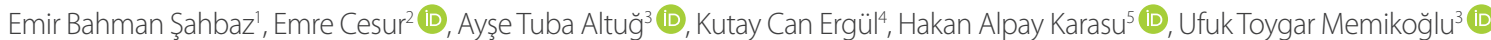

'Department of Orthodontics, Private Practice, Ankara, Turkey
2Department of Orthodontics, Medipol Mega University Hospital, Istanbul, Turkey
${ }^{3}$ Department of Orthodontics, Ankara University School of Dentistry, Ankara, Turkey
${ }^{4}$ Department of Oral and Maxillofacial Surgery, Private Practice, Istanbul, Turkey
${ }^{5}$ Department of Oral and Maxillofacial Surgery, Ankara University School of Dentistry, Ankara, Turkey

Cite this article as: Şahbaz EB, Cesur E, Altuğ AT, Ergül KC, Karasu HA, Memikoğlu UT. Is It Possible to Protract the Maxilla by Surgically Assisted Rapid Maxillary Expansion and Intermaxillary Class III Elastics? Turk J Orthod 2019; 32(2): 96-104.

\section{ABSTRACT}

Objective: The purpose of the present study was to evaluate skeletal and soft tissue changes with surgically assisted rapid maxillary expansion (SARME) and intermaxillary Class III elastics.

Methods: A total of 15 patients (mean age: 19.58 years) were included in the study. Each patient underwent SARME with the use of Class III elastics $(500 \mathrm{~g})$ applied through miniscrews to stimulate maxillary advancement. Lateral cephalograms and posteroanterior radiographs obtained before treatment ( $\mathrm{T} 1$ ), after SARME and elastic use (T2), and after treatment (T3) were analyzed to determine the changes in each phase of treatment. Planimeter was used to evaluate facial soft tissue changes. Wilcoxon signed-rank test was used to evaluate the changes that occur during treatment.

Results: SARME provided permanent and efficient maxillary expansion at both skeletal and dental levels $(p<0.01)$. Maxillary skeletal (ANS-Ver and U1i-Ver; $\mathrm{p}<0.01$ ) and soft tissue (Pr-Ver, Sn-Ver, and ULA-Ver; $\mathrm{p}<0.01$ ) variables and superior upper labial area (Area 1; $p<0.05$ ) increased due to maxillary dental and skeletal changes. Superior lower labial area (Area $3 ; p<0.05$ ) decreased as a result of slight increase in facial height and changes in maxillary-mandibular incisor relationship at the end of the treatment.

Conclusion: The results suggest that the improvement in the facial profiles of the patients is related to the significant increase in the bony and dental support of the upper lip region together with the contribution of the superior lower lip area.

Keywords: Class III elastics, maxillary retrusion, SARME, miniscrews

\section{INTRODUCTION}

Rapid maxillary expansion (RME) had been the gold standard for maxillary expansion in children and adolescents. However, it was reported that RME in adult patients can cause buccal tipping and extrusion of the posterior teeth, buccal root resorption, palatal tissue necrosis, pain, and other gingival complications (1-4).

In adult patients with both maxillary transverse deficiency and retrusion, the general treatment approach is primarily to perform surgically assisted rapid maxillary expansion (SARME) to correct the transversal problem and then to perform Le Fort I osteotomy to address the anteroposterior deficiency. With these approaches, patients must undergo two separate surgeries under general anesthesia. Undergoing multiple surgical procedures can increase the risk of complications, as well as prolong recovery time (5-7). It has been suggested in some studies that segmental Le Fort 1 osteotomies can be a more appropriate alternative to patients with transversal and/or sagittal discrepancies. This surgical method is considered to be useful, but some stability problems and complications were also reported (8-10).

Address for Correspondence: Emre Cesur, Department of Orthodontics, Medipol Mega University Hospital, İstanbul, Received: August 07, 2018 Turkey Accepted: October 31, 2018 
According to previous studies, corticotomy-assisted maxillary protraction can also be efficient to stimulate maxillary forward movement in younger individuals $(11,12)$. Although several studies have been published on the effects of either SARME, RME, or SARME-aided maxillary protraction with face masks or temporary anchorage devices for use of intermaxillary elastics (13-16), to the best of our knowledge, no study has been published evaluating the use of intermaxillary Class III elastics simultaneously with SARME in adult patients to facilitate maxillary advancement.

Hence, it was considered worthwhile to examine the effects of simultaneous implementation of SARME and intermaxillary Class III elastics on maxillary expansion and advancement.
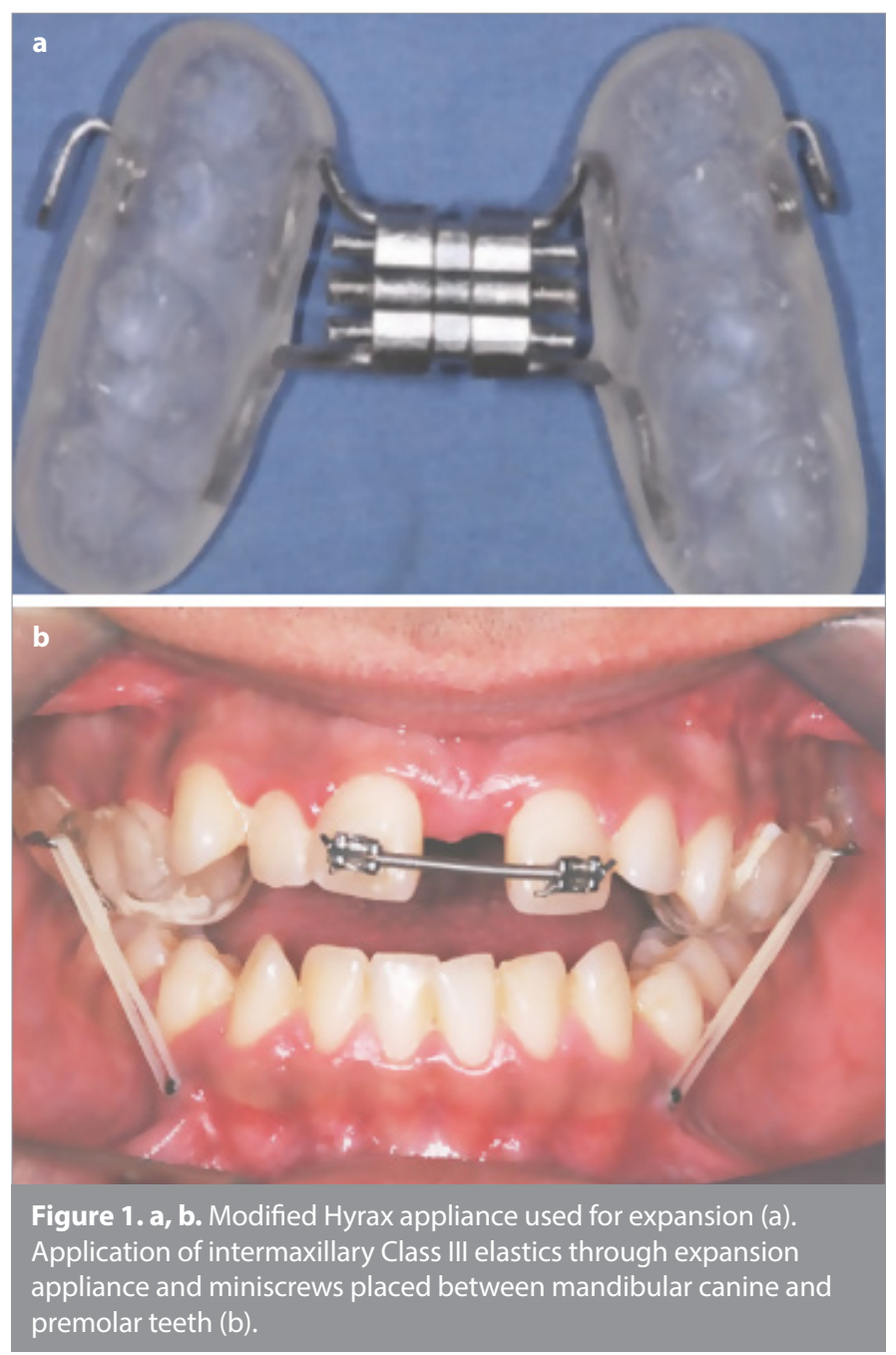

\section{METHODS}

\section{Subjects}

The study was approved by the ethics committee of Ankara University (IRB approval no.:B.30.3.ANK.0.21.63.00/824-02/9-8/126-2592). Informed consent was obtained from all patients prior to participation in the study. Sample size was calculated using the $G^{*}$ power 3.0.10 program (Universität Düsseldorf, Germany). Considering an alpha significance level of 0.05 and a statistical power of 0.80 , the study required at least 14 patients. A total of 15 ( 1 female and 14 male) patients were included in the study (Table 1). The mean age of the patients was 19.58 years. The patients included in the study were either in the latest growth stages or had completed growth according to the Greulich-Pyle hand-wrist atlas (17). They were all borderline orthognathic surgery subjects with skeletal Class III malocclusion and severe transverse maxillary deficiency with maxillary retrognathia.

1. Inclusion criteria were as follows:

2. posterior bilateral crossbite with skeletal involvement,

3. presence of Class III malocclusion associated with maxillary retrusion,

4. absence of congenital anomalies,

5. healthy periodontal status,

6. no history of orthodontic or surgical treatments prior to expansion.

\section{Treatment Protocol}

An occlusal-coverage modified Hyrax-type palatal expander was used in all patients. Stainless steel hooks $1 \mathrm{~mm}$ in thickness were embedded into the vulcanite on the buccal region of the palatal expander between premolar teeth (Figure 1).

All patients underwent SARME under general anesthesia performed by the same surgical team. The incisions were bilaterally performed at the depth of the vestibule. The mucoperiosteum was then elevated, and the maxillary bone was exposed from the pyriform aperture anteriorly to the pterygomaxillary fissure posteriorly. The pterygoid plates were separated from the maxilla. An additional vertical incision parallel to the labial frenulum was performed, and the maxilla was separated by malleting a thin osteotome through the suture between the maxillary central incisors.

While still under anesthesia, each patient received AbsoAnchor $^{\circledR}$ Golf Head-type miniscrews (diameter $1.6 \mathrm{~mm}$ and length $8 \mathrm{~mm}$; Dentos Inc., Taegu, South Korea) bilaterally between the roots of their mandibular canines and first premolars in attached gingiva and at an angle of $45^{\circ}$ to the occlusal plane, as well as Hyrax-type expansion appliances. After $24 \mathrm{~h}$ postoperatively, ex-

Table 1. Chronological ages of the patients and mean treatment times between treatment periods

\begin{tabular}{|lcccc|}
\hline Chronological Ages & Minimum Age (year) & Maximum Age (year) & Mean Age (year) & Treatment Duration (year) \\
\hline Pretreatment (T1) & 15.25 & 27.75 & 19.58 & 0.25 \\
Post-SARME and elastics (T2) & 15.50 & 28.00 & 19.83 & 1 \\
Post-treatment (T3) & 16.58 & 28.83 & 20.83 & 1.25 \\
Total (year) & & & & \\
\hline
\end{tabular}




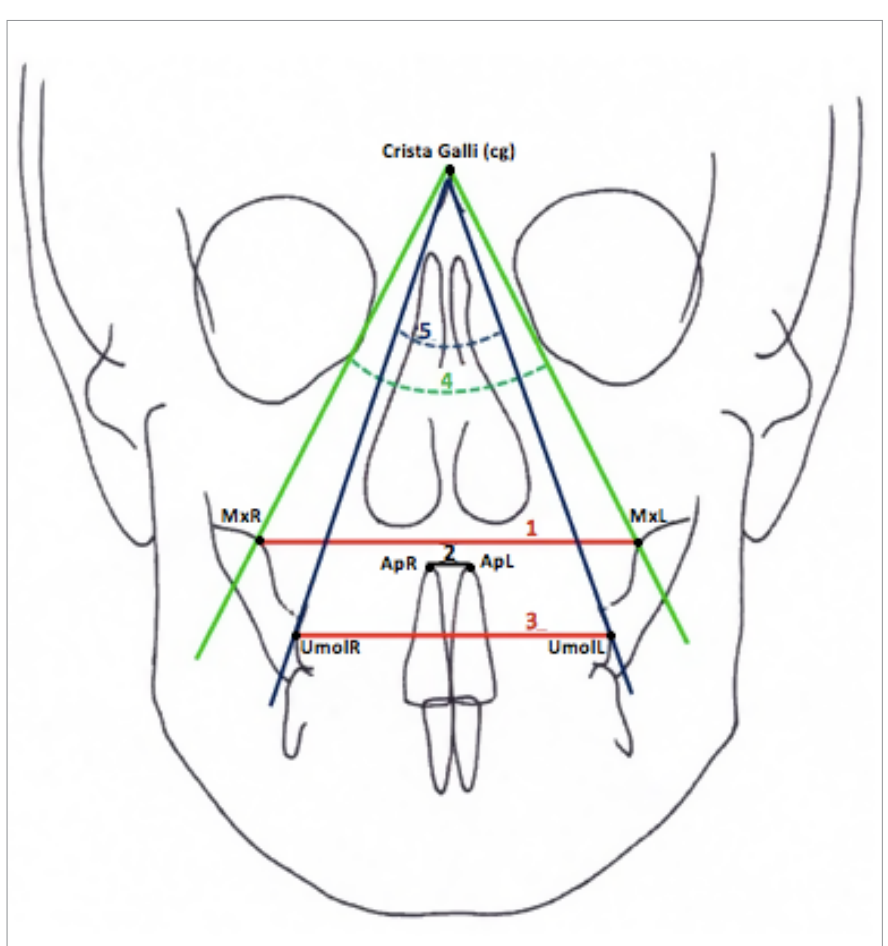

Figure 2. Posteroanterior measurements: $1:$ MxR-MxL (basal maxillary width), 2: ApR-ApL (linear distances between right and left maxillary central incisor apices), 3: UmolR-UmolL (maxillary dentoalveolar width), 4: MxR/Cg/MxL (angle between crista galli and maxillary base points), 5: UmolR/Cg/UmolL (angle between crista galli and maxillary molar points). pansion and maxillary advancement processes were initiated by attaching intermaxillary Class III elastics exerting $500 \mathrm{~g}$ of force to the miniscrews (Figure 1). The patients and their parents were instructed to activate the screws one turn in the morning and one turn in the evening ( $0.25 \mathrm{~mm}$ per turn). After expansion was complete, two braces were attached to the first incisors, and a 0.016 inch $\times 0.016$ inch Nitinol arch wire was applied. Close coil springs were placed between those incisors to prevent retrusion and unrestrained tipping of the incisors. Following this period, the expansion appliances were kept in place passively for 90 days postoperatively, and elastics application was continued.

The patients were then initiated to fixed appliance treatment, and intermaxillary elastics (150 $\mathrm{g}$ force) were continued to be applied between the maxillary molar-premolar teeth and the miniscrews. No precaution was taken except working with wide arch wires to preserve maxillary expansion. Three out of 30 miniscrews failed during treatment and were promptly replaced.

\section{Radiological Evaluation}

Pretreatment (T1), post-SARME and elastic use (T2), and posttreatment (T3) posteroanterior radiographs and lateral cephalograms were obtained for each patient. Five measurements were also made from posteroanterior radiographs to analyze the transversal changes (Figure 2). A constructed horizontal line was traced in a clockwise direction $7^{\circ}$ from the sella-nasion line. This line was considered as the horizontal reference (HR) plane, and perpendicular to the HR plane through the sella point was ac-
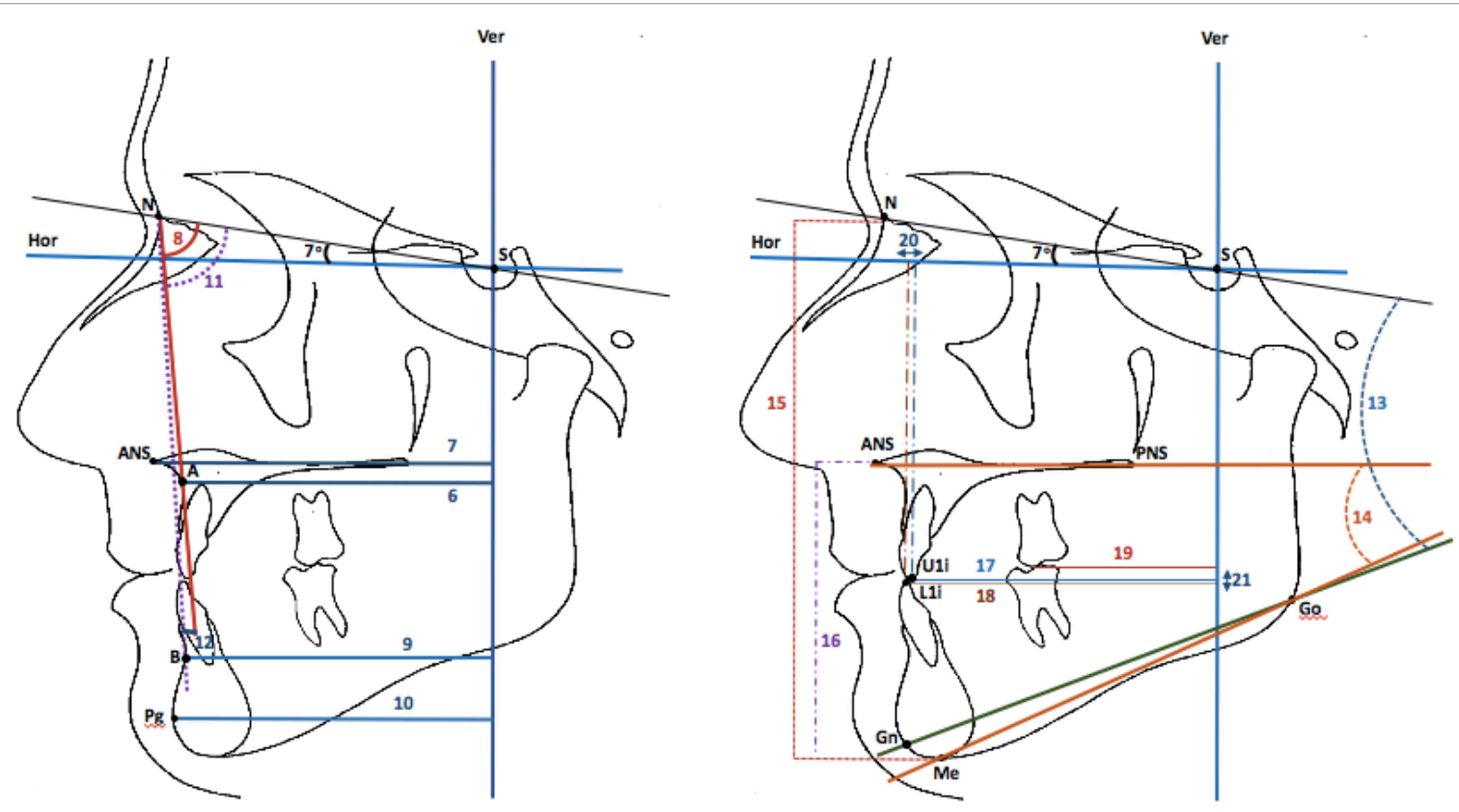

Figure 3. Maxillary skeletal measurements: 6: A-Ver (distance between point A and vertical reference plane), 7: ANS-Ver (distance between anterior nasal spine and vertical reference plane), 8: SNA (posteroinferior angle between anterior cranial base and nasion-point A line). Mandibular skeletal measurements: 9: B-Ver (distance between point B and vertical reference plane), 10: Pg-Ver (distance between pogonion and vertical reference plane), 11: SNB (posteroinferior angle between anterior cranial base and nasion-point B line). Maxillomandibular skeletal measurements: 12: ANB (angle between nasion-point A and nasion-point B lines). Vertical skeletal measurements: 13: SN/Go-Gn (angle between anterior cranial base and mandibular plane), 14: ANS-PNS/Go-Me (angle between palatal plane and mandibular plane), 15: N-Me (total anterior facial height), 16: ANS-Me (anterior lower facial height). Dentoalveolar measurements: 17: U1i-Ver (distance between incisal edge of the upper central incisor and vertical reference plane), 18: L1i-Ver (distance between incisal edge of the lower central incisor and vertical reference plane), 19: U6-Ver (distance between upper first molar and vertical reference plane), 20: overjet, 21: overbite. 


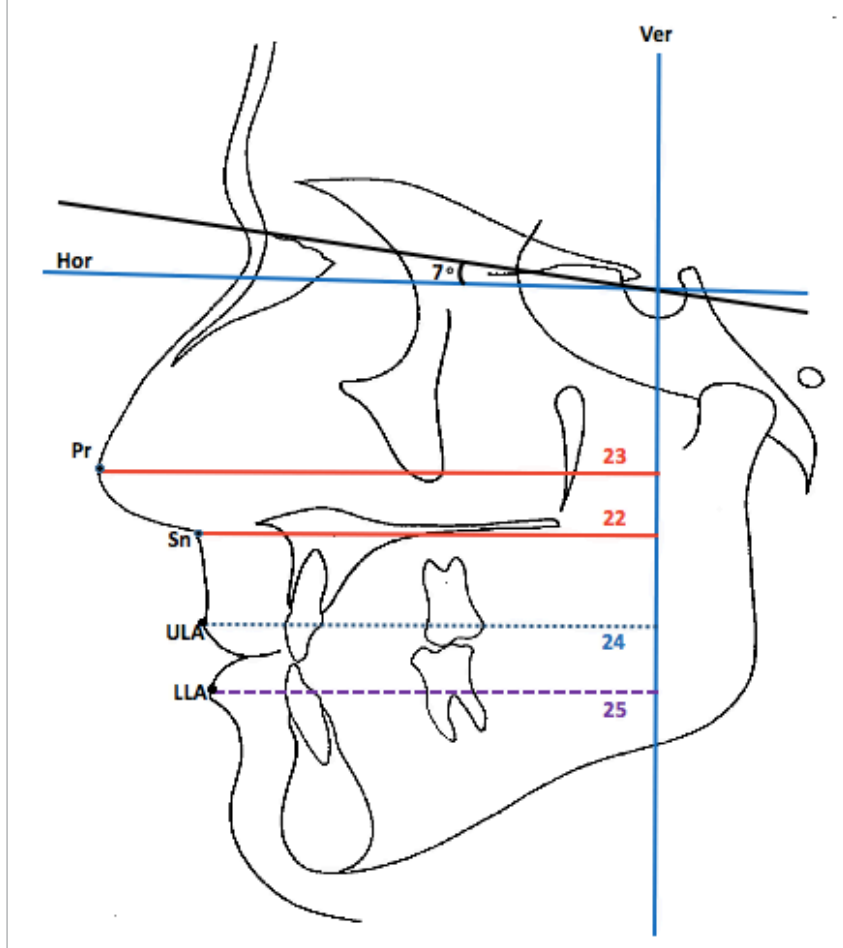

Figure 4. Soft tissue measurements: 22: Sn-Ver (distance between subnasale point and vertical reference plane), 23: Pr-Ver (distance between pronasale point and vertical reference plane), 24: ULA-Ver (distance between the most anterior point of the upper lip and vertical reference plane), 25: LLA-Ver (distance between the most anterior point of the lower lip and vertical reference plane)

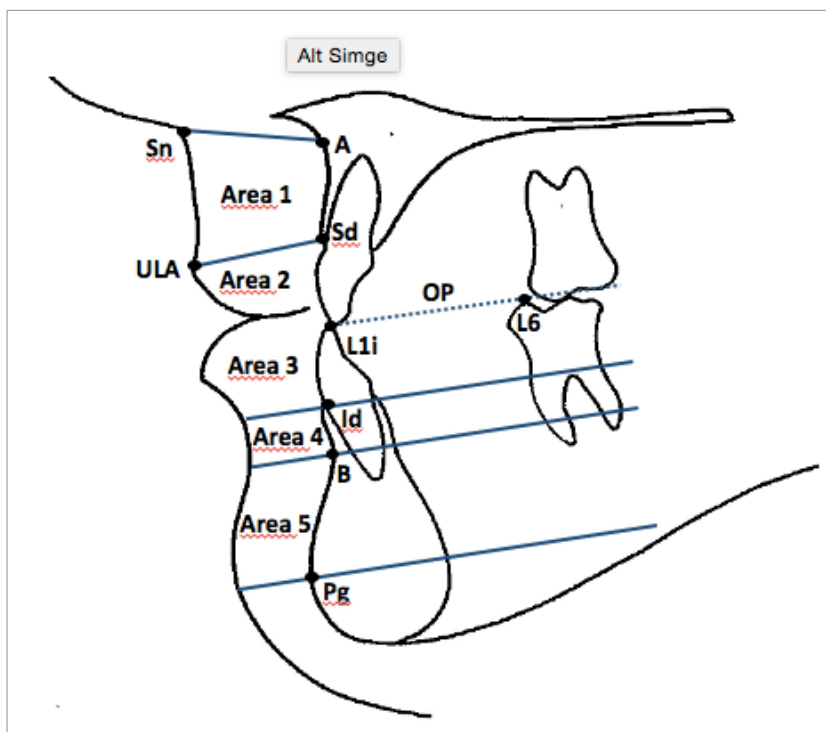

Figure 5. Planimetric area measurements: The upper lip was divided into two parts (Areas 1 and 2). 26: Area 1: superior upper labial area; the area between point $A$, subnasal, upper lip anterior, and supradental point. 27: Area 2: inferior upper labial area; the area below supradental and upper lip anterior line. The lower lip was divided into three parts (Areas 3,4, and 5) from the incisal edge of the mandibular central incisor (L1i), infradentale (Id), point B, and pogonion point. Lines dividing the lower lip area were constructed parallel to the mandibular occlusal plane. 28: Area 3: superior lower labial area, 29: Area 4: middle lower labial area, 30: Area 5: inferior lower labial area
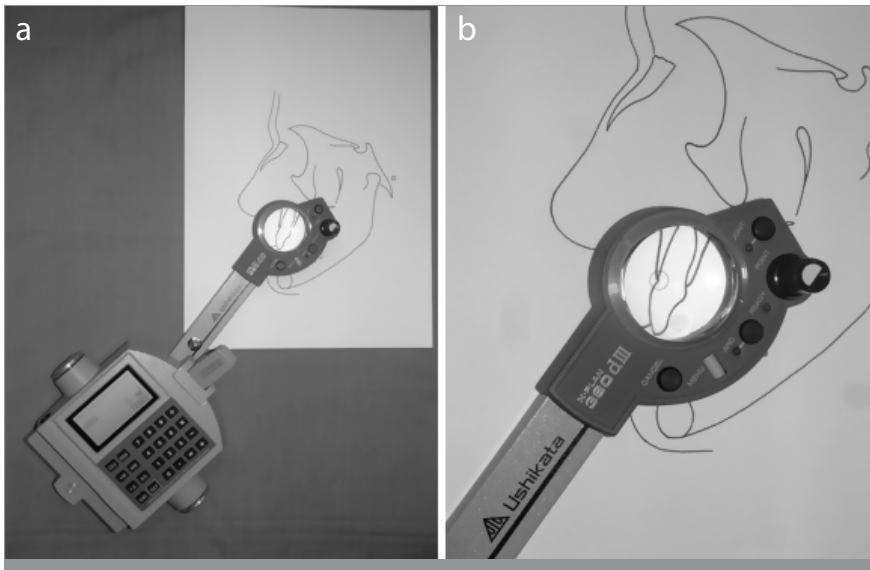

Figure 6. a, b. (a) Digital planimeter. (b) Measurement of the areas using the digital planimeter (18)

cepted as the vertical reference plane (Ver). The presented cephalometric hard tissue (Figure 3 ) and soft tissue (Figure 4) measurements were made from lateral cephalograms using PorDios (Purpose on Request Digitizer Input Output System, trademark of the Institute of Orthodontic Computer Science, Aarhus, Denmark) cephalometric analysis program.

Changes in labial areas were evaluated by dividing the lip region into five sections (Figure 5) (18). Labial area measurements were also made from cephalometric charts using a digital planimeter (Ushikata X-PLAN380 dll/460 dll, Tokyo, Japan). To achieve this, the cephalometric films were transferred onto paper using a $0.3 \mathrm{~mm}$ pencil, and the specified areas were marked (Figure 6).

\section{Statistical Analysis}

Statistical analyses were performed using the Statistical Package for Social Sciences (IBM Corp.; Armonk, NY, USA) version 20.0. Descriptive statistics were calculated for all measurements, as well as the between-stage changes. The correlation coefficients were calculated to assess the reliability of the method. Wilcoxon signed-rank test was used to compare T2-T1, T3-T2, and T3-T1 changes of cephalometric and posteroanterior measurements.

\section{RESULTS}

Lateral cephalometric and posteroanterior radiographs of eight patients were randomly selected. All measurements were digitized twice by the same observer at an interval of 1 month to determine intraobserver variability. The reliability of the method was high, with correlation coefficients ranging between 0.81 and 1 .

\section{Changes in Posteroanterior Radiographic Measurements}

Posteroanterior radiographs obtained during the expansion phase (T1-T2) revealed significant increases in the MxR-MxL, UMoIR-UMolL, and ApR-ApL distances $(p<0.01)$ and $M \times R / C g /$ $\operatorname{MxL}(p<0.01)$ and UmolR/Cg/UmolL angles $(p<0.05)$, which indicate tipping of the maxillary segments and of the maxillary molars. Although significant decreases were observed in the dental parameters $(p<0.05)$ during the T3-T2 period, permanent maxillary expansion was provided at both the skeletal and dental levels at the end of the treatment period $(p<0.01$; Table 2$)$. 
Table 2. Mean pretreatment (T1) values of posteroanterior parameters and the changes occured during SARME and elastic use (A; T2-T1); between SARME and elastic use and posttreatment periods (B; T3-T2); pretreatment and posttreatment periods (C; T3-T1) by Wilcoxon Sign Test

\begin{tabular}{|c|c|c|c|c|c|c|c|}
\hline \multirow[b]{2}{*}{ Parameters } & \multirow{2}{*}{$\begin{array}{c}\mathrm{T} 1 \\
\mathrm{X} \pm \mathrm{Sx}\end{array}$} & \multicolumn{2}{|c|}{ T2-T1 } & \multicolumn{2}{|c|}{ T3-T2 } & \multicolumn{2}{|c|}{ T3-T1 } \\
\hline & & $\mathbf{D} \pm \mathbf{S d}$ & Test & $\mathbf{D} \pm S d$ & Test & $\mathbf{D} \pm \mathbf{S d}$ & Test \\
\hline \multicolumn{8}{|c|}{ Posteroanterıor Measurements } \\
\hline 2. ApR-ApL (mm) & $6.82 \pm 0.35$ & $3.58 \pm 0.64$ & ** & $-2.37 \pm 0.63$ & * & $1.21 \pm 0.40$ & * \\
\hline 3. UmolR-UmolL (mm) & $60.48 \pm 1.40$ & $6.78 \pm 0.81$ & ** & $-1.91 \pm 0.75$ & * & $4.87 \pm 0.67$ & $* *$ \\
\hline
\end{tabular}

Table 3. Mean pretreatment (T1) values of cephalometric skeletal/dentoalveolar parameters and changes occurring during SARME and elastic use (A; T2-T1); between SARME and elastic use and posttreatment periods (B; T3-T2); pretreatment and posttreatment periods (C; T3-T1) by Wilcoxon Sign Test

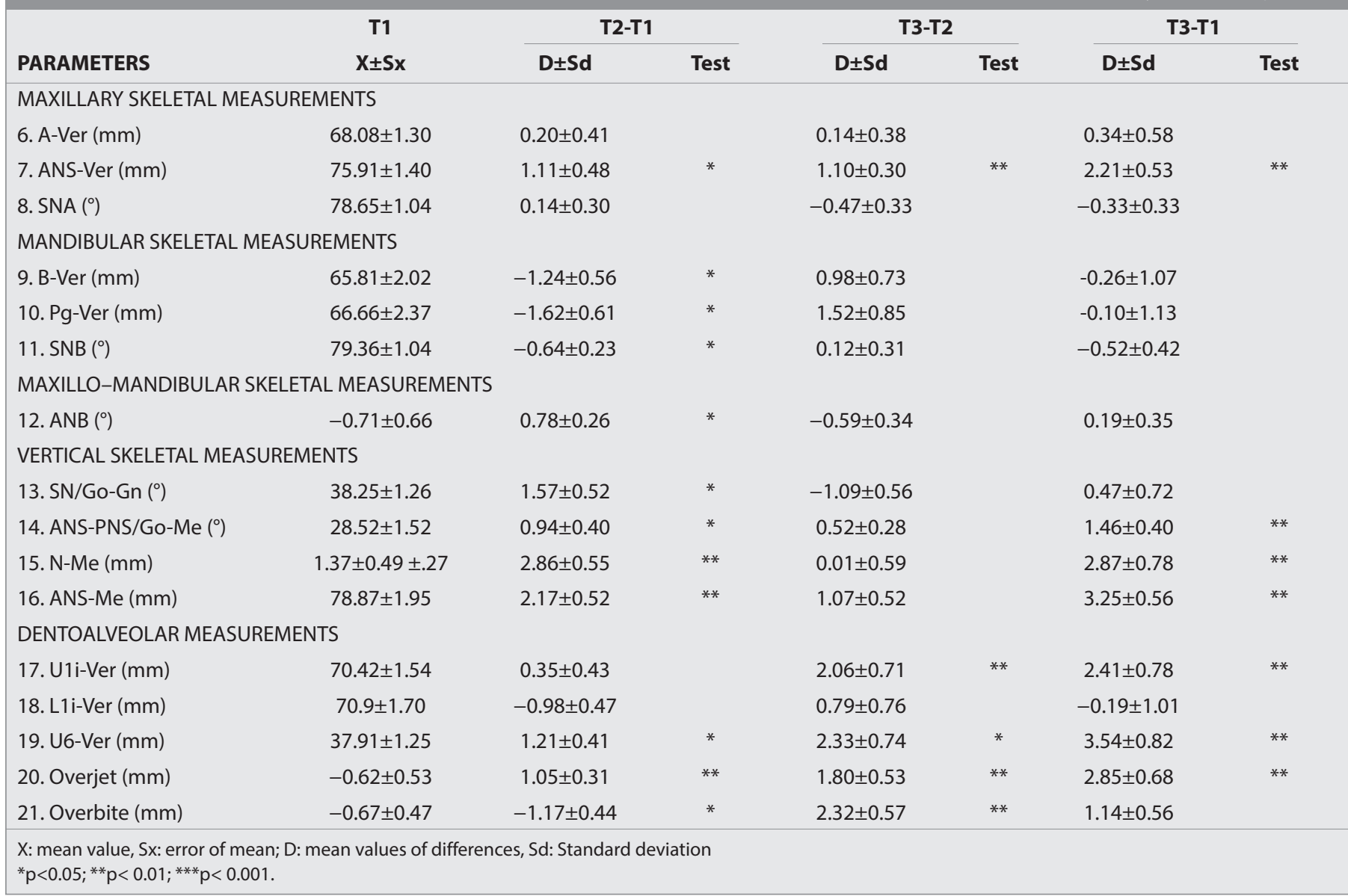

\section{Changes in Lateral Cephalometric Measurements}

\section{Maxillomandibular Changes}

The ANS-Ver value increased significantly in all treatment periods, indicating anterior movement of the anterior nasal spine. Significant changes were also observed in SNB, B-Ver, and Pg-Ver values and ANB in the T2-T1 period ( $p<0.05$; Table 3$)$.

\section{Vertical Changes}

Significant increases were observed in the ANS-PNS/Go-Me angle, then in the N-Me and ANS-Me values, $(p<0.01)$, and in the Go-Gn/SN angle $(p<0.05)$, indicating the posterior rotation of the mandible and the increase of the anterior facial height (Table 3).

\section{Dental Changes}

The incisal edge of the maxillary central incisor moved anteriorly in the T3-T2 and T3-T1 periods (U1i-Ver; $\mathrm{p}<0.01$ ), whereas the sagittal position of the mandibular incisor (L1i-Ver) did not change significantly. Maxillary first molar also moved anteriorly in all time points (U6-Ver). Both overjet and overbite increased at the end of the treatment $(p<0.01$; Table 3$)$. 
Table 4. Mean pretreatment (T1) values of soft tissue parameters and changes occurring during SARME and elastic use ( $\mathrm{A} ; \mathrm{T} 2-\mathrm{T} 1)$; between SARME and elastic use and posttreatment periods (B; T3-T2); pretreatment and posttreatment periods (C; T3-T1) by Wilcoxon Sign Test

\begin{tabular}{|c|c|c|c|c|c|c|c|}
\hline \multirow[b]{2}{*}{ PARAMETERS } & \multirow{2}{*}{$\begin{array}{c}\text { T1 } \\
\mathrm{X} \pm \mathrm{Sx}\end{array}$} & \multicolumn{2}{|c|}{ T2-T1 } & \multicolumn{2}{|c|}{ T3-T2 } & \multicolumn{2}{|c|}{ T3-T1 } \\
\hline & & $\mathrm{D} \pm \mathrm{Sd}$ & Test & $\mathrm{D} \pm \mathrm{Sd}$ & Test & $\mathrm{D} \pm \mathrm{Sd}$ & Test \\
\hline \multicolumn{8}{|c|}{ SOFT TISSUE MEASUREMENTS } \\
\hline 23. Pr-Ver (mm) & $105.97 \pm 1.46$ & $1.04 \pm 0.51$ & * & $1.06 \pm 0.35$ & $* *$ & $2.10 \pm 0.71$ & ** \\
\hline 24. ULA-Ver (mm) & $88.39 \pm 1.77$ & $-0.90 \pm 0.61$ & & $2.34 \pm 0.71$ & $* *$ & $1.45 \pm 0.57$ & * \\
\hline 26. AREA $1\left(\mathrm{~mm}^{2}\right)$ & $220.61 \pm 48.10$ & $7.21 \pm 27.52$ & & $27.26 \pm 46.75$ & * & $30.48 \pm 42.62$ & \\
\hline 27. AREA $2\left(\mathrm{~mm}^{2}\right)$ & $114.04 \pm 36.51$ & $-2.49 \pm 24.80$ & & $-8.75 \pm 19.91$ & & $-11.25 \pm 23.79$ & \\
\hline 28. AREA $3\left(\mathrm{~mm}^{2}\right)$ & $178.52 \pm 26.11$ & $9.43 \pm 24.28$ & & $-16.14 \pm 23.65$ & * & $-6.7 \pm 20.37$ & \\
\hline 29. AREA $4\left(\mathrm{~mm}^{2}\right)$ & $134.02 \pm 65.67$ & $13.64 \pm 61.28$ & & $-4.34 \pm 68.91$ & & $9.29 \pm 35.91$ & \\
\hline
\end{tabular}

Table 5. Summary of the relationship between linear soft tissue and skeletal tissue changes of maxillary-mandibular components and upperlower lip areas between posttreatment and pretreatment periods (T3-T1)

\begin{tabular}{|c|c|c|c|c|c|}
\hline \multirow[b]{2}{*}{ Area } & \multicolumn{2}{|r|}{ Hard Tissue } & \multicolumn{3}{|c|}{ Soft Tissue } \\
\hline & D & & D & & D \\
\hline \multicolumn{6}{|c|}{ Maxillary Variables } \\
\hline \multirow{2}{*}{ AREA $1\left(\mathrm{~mm}^{2}\right)$} & & A-Ver $(\mathrm{mm})$ & 0.34 & Sn-Ver (mm) & 1.81 \\
\hline & & ANS-Ver (mm) & $2.21^{* *}$ & & \\
\hline \multicolumn{6}{|c|}{ Mandibular and Maxillomandibular Variables } \\
\hline \multirow[t]{2}{*}{ AREA $3\left(\mathrm{~mm}^{2}\right)$} & -6.7 & L1i-Ver (mm) & -0.2 & LLA-Ver (mm) & 0.57 \\
\hline & & ANS-Me (mm) & $3.24^{* *}$ & & \\
\hline AREA $4\left(\mathrm{~mm}^{2}\right)$ & 9.29 & B-Ver $(\mathrm{mm})$ & -0.26 & & \\
\hline AREA $5\left(\mathrm{~mm}^{2}\right)$ & 21.05 & Pg-Ver (mm) & -0.10 & & \\
\hline
\end{tabular}

\section{Soft Tissue Changes}

The tip of the nose (Pr-Ver) and the subnasale point (Sn-Ver) moved forward in all observation stages (Table 4). The anterior movement of the upper lip (ULA-Ver) was also significant in the T3-T2 $(p<0.01)$ and T3-T1 $(p<0.05)$ periods (Table 4). The lower lip (LLA-Ver) moved significantly at the posterior direction during the expansion period $(\mathrm{p}<0.05 ; \mathrm{T} 2-\mathrm{T} 1)$, whereas an anterior movement was observed during the fixed treatment (T3-T2) period ( $p<0.05$; Table 4).

\section{Changes in Lip Area Measurements}

Area 1 (superior upper lip area) did not change significantly between T2 and T1, whereas significant increases were observed in the T3-T2 and T3-T1 periods ( $p<0.05$; Table 4). Area 3 (superior lower lip area) significantly decreased between T3 and T2 ( $p<0.05$; Table 4).

The summary of the correlation between linear soft and skeletal tissue changes of maxillary-mandibular components and upper-lower lip areas between pre- and posttreatment periods (T3-T1) is presented in Table 5 . It could be summarized that the increase in Area 1 is related with the forward movement of ANS and maxillary incisors, whereas the decrease in Area 3 could be correlated with the increase in anterior facial height (ANS-Me).

\section{DISCUSSION}

SARME is the primary surgical approach for adults with maxillary transverse deficiency (19). Some previous studies reported that SARME can also be applied in younger individuals to stimulate maxillary protraction (11-13). Küçükkeleş et al. (13) applied face mask together with Le Fort I osteotomy in adolescent patients to enhance the protraction effect. They compared the results of this approach with RME+face mask and claimed that Le Fort I+face mask results in significantly more advancement. There are also studies examining the effects of temporary anchorage devices for maxillary protraction (14-16). However, to our knowledge, there is no study evaluating the effects of intermaxillary Class III elastics simultaneously with SARME in adult patients. Therefore, the purpose of the present study was to evaluate whether simultaneous maxillary expansion and advancement could be achieved with a single surgical procedure and an intraoral anchorage system. 
An occlusal-coverage bonded palatal expander was used for all patients in the present study. Toygar Memikoğlu et al. (20) claimed that although satisfactory treatment results can be achieved with both bonded and banded palatal expanders, dentoalveolar response is more with banded appliances. Therefore, a bonded appliance that was acrylic-coated on the occlusal surfaces was used to prevent dental effects.

In the present study, posteroanterior radiographs obtained during the expansion phase indicated tipping of the maxillary segments and of the maxillary molars, respectively. During fixed treatment, decreases were observed in these parameters. The statistically nonsignificant decrease in the $M x R / C g / M x L$ angle also demonstrates that the expansion achieved in our study was stable at the skeletal level. Based on these results, it can be concluded that the primary goal of the present study was successfully achieved as permanent maxillary expansion was provided at both the skeletal and dental levels. These findings are consistent with previous long-term studies on $\operatorname{RME}$ and $\operatorname{SARME}(21,22)$

According to the results of the present study, there were no significant differences in parameters associated with the position of point A, whereas ANS moved forward $1.11 \mathrm{~mm}$ in the T2-T1 period (Table 3). Vardimon et al. (23) attributed high relapse rates following maxillary expansions with 90 -day retention to the new bone being immature and easily resorbed under pressure. These bony changes have a direct effect on the position of point A. We also left the devices for an average of 3 months for retention. Therefore, the inability to cephalometrically evaluate advancement of point $A$ during the expansion period could be attributed to the appearance of immature bone not showing sufficient radiopacity in that region. However, when we reevaluated maxillary parameters at the end of the treatment, the movement of point A was still insignificant although ANS moved forward $2.21 \mathrm{~mm}$ in total $(p<0.01$; Table 3$)$. In our study groups, the pterygoid processes were separated during surgery, which hypothetically should facilitate the forward movement of the maxilla. Studies by Biederman (24) and Liou (25) revealed that surgical weakening of the pterygoid processes may have caused their resorption during expansion, or the maxilla may have expanded in a more parallel direction instead of a V-shape. In fact, the $6.78 \mathrm{~mm}$ increase between the maxillary molars (UmolR-UmolL) and the $3.58 \mathrm{~mm}$ increase between the maxillary central incisors (ApR-ApL) demonstrate that the posterior region expanded more than the anterior region (Table 2). We believe that these findings corroborate why point A did not show as much advancement as expected in the long term. The position of point A may also be influenced by local remodeling associated with the proclination of upper incisors $(26,27)$. It should be noted that significant protrusion of upper incisors was observed in the present study (Table 3 ). The insignificantly mild retrusion of point $A$ observed in our study may also be explained by the proclination of upper incisors with backward movement of incisor root apexes.

Although these changes in maxillary skeletal parameters may introduce uncertainty regarding the success of maxillary advancement, we observed favorable changes in the profiles of patients included in the study. Based on soft tissue measurements, significant increases were observed in the pronasale and subnasale points. Changes in both of these parameters can be associated with forward movement of the anterior nasal spine. Although we observed a statistically nonsignificant retrusion in the upper lip during the expansion and protraction period, protrusion in the fixed treatment period was significantly consistent with maxillary incisor movement. Previous studies have shown that lip thickness and position can be affected by incisor movement $(28,29)$. Consistent with these changes, Area 1, representing the superior upper lip area, increased significantly in the T3-T2 and T3-T1 periods. In a study using similar methods to analyze soft tissue changes following bimaxillary surgery, Altug-Atac et al. (18) reported substantial increases in $\mathrm{Pr}$ and Sn points, but in contrast to our findings observed a decrease in Area 1. They attributed this to compression of the lip area due to significant forward movement of the maxilla and point A caused by Le Fort I surgery. Although advancement of the maxilla as a whole may compress soft tissue in patients undergoing orthognathic surgery, the more restricted movement in our study and the aforementioned immature structure may explain why we observed an increase in Area 1 (Table 4).

In our assessment of the lower lip position, although lower lip significantly retruded during the expansion and protraction period, a slight protrusion was observed during the fixed orthodontic treatment period. This change in lower lip position may be due to the position of lower incisor showing mild retrusion between $\mathrm{T} 2$ and $\mathrm{T} 1$ and protrusion between $\mathrm{T} 3$ and $\mathrm{T} 2$ periods or may be associated with increases in the vertical facial dimensions occurring during the expansion and protraction period. Area 3, representing the superior lower lip, decreased significantly between T3 and T2. The soft and flexible structure of the lower lip makes it easily affected by tooth movements and musculature (30). In addition to the changes observed in the vertical dimension, we believe that the lip may show backward movement due to the favorable changes in overjet and overbite at the end of the treatment. According to our results, correction of the dental relationship in particular resulted in curling of the superior aspect of the lower lip, which created favorable profile changes in our patients (Table 5).

Another treatment option for adult patients with skeletal Class III malocclusion who are not willing to undergo Le Fort-maxillary advancement surgery is camouflage treatment. The results of the present study could also be interpreted as a camouflage due to the protrusion of maxillary incisors during the fixed orthodontic treatment stage. Additionally, we observed maxillary molar mesialization all through the treatment stages. One of the most favorable findings of the study could be defined as achieving the mesial movement of maxillary dental arch without any undesirable mandibular incisor retrusion. It is well-known that the undesirable movement of mandibular incisors inside the narrow symphysis of the mandibles of Class III subjects could solely cause additional dental complications. Therefore, the application of Class III elastics through miniscrews should get all the credit in avoiding these unfavorable dental movements. 


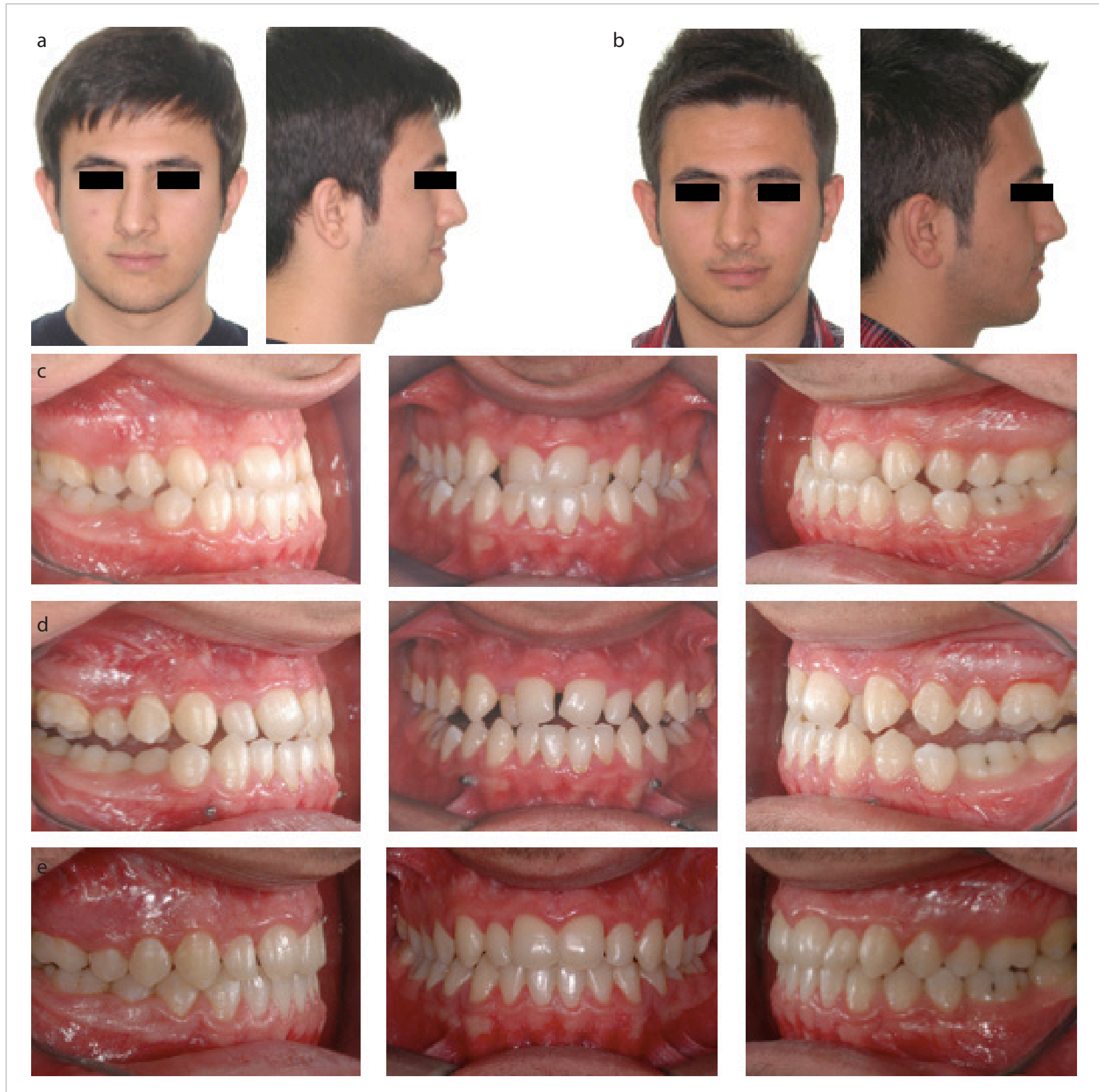

Figure 4. a-e. Photos of a patient treated with SARME/intermaxillary Class III elastic procedure and fixed orthodontic treatment. (a) Pretreatment (T1) extraoral photos. (b) Posttreatment (T3) extraoral photos. (c) Pretreatment (T1) intraoral photos. (d) Post-SARME and elastic use (T2) intraoral photos. (e) Posttreatment (T3) intraoral photos

\section{CONCLUSION}

The patients included in our study were borderline orthognathic surgical cases. A successful maxillary expansion was achieved in all subjects at the skeletal level. There was no need for a secondary and more likely a bimaxillary surgery in any of the subjects with the application of Class III elastics and SARME (Figure 7). Significant forward movement of the ANS and midfacial soft tissues provided a positive answer to our null hypothesis of whether SARME and Class III elastics applied simultaneously can stimulate maxillary advancement.
Nevertheless, if this procedure is considered in patients with maxillary transverse deficiency and retrusion, patient selection must be conducted carefully, and the patient and their family should be informed of the possibility of a second surgery.

Ethics Committee Approval: Ethics committee approval was received for this study from the Ethics Committee of Ankara University (IRB approval no.: B.30.3.ANK.0.21.63.00/824-02/9-8/126-2592).

Informed Consent: Written informed consent was obtained from the subjects who participated in this study. 
Peer-review: Externally peer-reviewed.

Author Contributions: Concept - A.T.A.; Design - A.T.A.; Data Collection and/or Processing - E.B.Ş., K.C.E., H.A.K.; Analysis and/or Interpretation - E.B.Ş., E.C.; Literature Search - E.B.Ş., E.C., A.T.A., U.T.M.; Writing Manuscript - E.B.Ş., E.C.; Critical Review - A.T.A., U.T.M.

Conflict of Interest: The authors have no conflict of interest to declare.

Financial Disclosure: The authors declared that this study has received no financial support.

\section{REFERENCES}

1. Zimring JF, Isaacson RJ. Forces produced by rapid maxillary expansion. III. Forces present during retention. Angle Orthod 1965; 35: 178-86.

2. Wertz RA. Skeletal and dental changes accompanying rapid midpalatal suture opening. Am J Orthod 1970; 58: 41-66. [CrossRef]

3. Timms DJ. A study of basal movement with rapid maxillary expansion. Am J Orthod 1980; 77: 500-7. [CrossRef]

4. Suri L, Taneja P. Surgically assisted rapid palatal expansion: a literature review. Am J Orthod Dentofac Orthop 2008; 133: 290-302. [CrossRef]

5. Bell WH, Epker BN. Surgical-orthodontic expansion of the maxilla. Am J Orthod 1976; 70: 517-28. [CrossRef]

6. Furquim LZ, Janson G, Furquim BD, Filho LI, Henriques JFC, Ferreira GM. Maxillary protraction after surgically assisted maxillary expansion. J Appl Oral Sci 2010; 18: 308-15. [CrossRef]

7. Parello D, Bolamperti L, Caprioglio A. Interdisciplinary treatment of Class III malocclusion: a case report. Prog Orthod 2011; 12: 169-79. [CrossRef]

8. Marchetti C, Pironi M, Bianchi A, Musci A. Surgically assisted rapid palatal expansion vs. segmental Le Fort I osteotomy: Transverse stability over a 2-year period. J Craniomaxillofac Surg 2009; 37: 74-8. [CrossRef]

9. Janson M, Janson G, Sant'ana Eduardo, Nakamura A, de Freitas MR. Segmental Lefort I osteotomy for treatment of a class III malocclusion with temporomandibular disorder. J Appl Oral Sci 2008; 16: 302-9. [CrossRef]

10. Haas Junior OL, Guijarro-Martínez R, de Sousa Gil AP, da Silva MeireIles L, de Oliveira RB, Hernández-Alfaro F. Stability and surgical complications in segmental Le Fort I osteotomy: a systematic review. Int J Oral Maxillofac Surg 2017; 46: 1071-87.[CrossRef]

11. Yilmaz HN, Garip H, Satilmis T, Kucukkeles N. Corticotomy-assisted maxillary protraction with skeletal anchorage and Class III elastics. Angle Orthod 2015; 85: 48-57. [CrossRef]

12. Nevzatoğlu Ş, Küçükkeleş N. Long-term results of surgically assisted maxillary protraction vs regular facemask. Angle Orthod 2014; 84: 1002-9. [CrossRef]

13. Küçükkeleş N, Nevzatoğlu Ş, Koldaş T. Rapid maxillary expansion compared to surgery for assistance in maxillary face mask protraction. Angle Orthod 2011; 81: 42-9. [CrossRef]
14. Wilmes B, Nienkemper M, Ludwig B, Kau CH, Drescher D. Early Class III treatment with a Hybrid Hyrax-Mentoplate combination. J Clin Orthod 2011; 45: 15-21.

15. De Clerck HJ, Cornelis MA, Cevidanes LH, Heymann GC, Tulloch CJ. Orthopedic traction of the maxilla with miniplates: A new perspective for treatment of midface deficiency. J Oral Maxillofac Surg 2009; 67: 2123-9. [CrossRef]

16. Heymann GC, Cevidanes L, Cornelis M, De Clerck HJ, Tulloch JF. Three-dimensional analysis of maxillary protraction with intermaxillary elastics to miniplates. Am J Orthod Dentofac Orthop 2010; 137: 274-84. [CrossRef]

17. Greulich WW, Pyle SI. Radiographic atlas of skeletal development of hand and wrist. 2nd Ed. Stanford: Stanford University Press; 1959. [CrossRef]

18. Altug-Atac AT, Bolatoglu $H$, Memikoglu UT. Facial soft tissue profile following bimaxillary orthognatic surgery. Angle Orthod 2008; 78: 50-7. [CrossRef]

19. Altuğ-Ataç AT, Karasu HA, Aytaç D. Surgically assisted rapid maxillary expansion compared with orthopedic rapid maxillary expansion. Angle Orthod 2006; 76: 353-9.

20. Toygar Memikoğlu TU, işseri H, Uysal ME. Comparison of dentofacial changes with rigit acrylic bonded and Haas type banded rapid maxillary expansion devices. Turk J Orthod 1997; 10: 255-64. [CrossRef]

21. Bishara SE, Staley RN. Maxillary expansion: Clinical implications. Am J Orthod Dentofac Orthop 1987; 91: 3-14. [CrossRef]

22. Bays RA, Greco JM. Surgically assisted rapid palatal expansion: an outpatient technique with long-term stability. J Oral Maxillofac Surg 1992; 50: 110-3. [CrossRef]

23. Vardimon AD, Brosh T, Spiegler A, Lieberman M, Pitaru S. Rapid palatal expansion: Part 1. Mineralization pattern of the mid palatal suture in cats. Am J Orthod J Dentofac Orthop 1998; 113: 371-8. [CrossRef]

24. Biederman W. Rapid correction of class III malocclusion by midpalatal expansion. Am J Orthod 1973; 63: 47-55. [CrossRef]

25. Liou E. Interview with Eric Liou. R Dental Press Ortodon Ortop Facial 2009; 14: 27-37. [CrossRef]

26. Al-Nimri KS, Hazza'a AM, Al-Omari RM. Maxillary incisor proclination effect on the position of point $A$ in class II division 2 malocclusion. Angle Orthod 2009; 79: 880-4. [CrossRef]

27. Chen $Q$, Zhang C, Zhou Y. The effects of incisor inclination changes on the position of point A in Class II division 2 malocclusion using three-dimensional evaluation: a long-term prospective study. Int J Clin Exp Med 2014; 7: 3454-60.

28. Oliver BM. The influence of lip thickness and strain on upper lip response to incisor retraction. Am J Orthod 1982; 82: 141-9. [CrossRef]

29. Talass MF, Tollaae L, Baker RC. Soft-tissue profile changes resulting from retraction of maxillary incisors. Am J Orthod J Dentofac Orthop 1987; 91: 385-94. [CrossRef]

30. Sarver DM, Weissman SM. Long-term soft tissue response to Le Fort I maxillary superior repositioning. Angle Orthod 1991; 61: 267-76. 